\title{
Wave attenuation by submerged vegetation: combining the effect of organism traits and tidal current
}

\author{
M. Paul ${ }^{1,3, *}$, T. J. Bouma ${ }^{2}$, C. L. Amos ${ }^{1}$ \\ ${ }^{1}$ National Oceanography Centre, University of Southampton, Southampton SO14 3ZH, UK \\ ${ }^{2}$ Netherlands Institute of Ecology, Centre for Estuarine and Marine Ecology, $4400 \mathrm{AC}$ Yerseke, The Netherlands \\ ${ }^{3}$ Present address: Forschungszentrum Küste, 30419 Hannover, Germany
}

\begin{abstract}
Accurate wave height prediction along the shore plays an important role in coastal protection and management. To account for the effect of submerged vegetation in waveattenuation models, it is important to understand how the interaction between vegetation characteristics and hydrodynamic forcing affects wave attenuation. To determine the effect of vegetation characteristics, we used seagrass mimics that varied in (1) blade stiffness, (2) shoot density and (3) leaf length; to investigate the effect of hydrodynamic forcing, we studied wave attenuation in the absence and presence of a tidal current. Results show that wave attenuation is positively correlated with blade stiffness and for a given wave in shallow water, attenuation is dependent on a combination of shoot density and leaf length, which can be described by the leaf area index. The presence of a tidal current strongly reduced the wave-attenuating capacity of seagrass mimics, and this reduction was most pronounced at high shoot densities. Thus, most studies that have been carried out under waves only will structurally overestimate wave attenuation for tidal environments, emphasising that tidal currents need to be taken into account in future studies on wave attenuation by vegetation.
\end{abstract}

KEY WORDS: Waves $\cdot$ Currents · Artificial seagrass $\cdot$ Vegetation traits $\cdot$ Wave attenuation Resale or republication not permitted without written consent of the publisher

\section{INTRODUCTION}

The interaction of seagrass with hydrodynamics is widely recognised to affect sediment dynamics (Fonseca 1996), coastal erosion (Stein et al. 1989) and ecological processes such as nutrient transport and pollen dispersal (Verduin et al. 2002). Seagrass reduces flow velocities (Fonseca \& Fisher 1986), and it has been shown for a variety of seagrass species that submerged seagrass vegetation can significantly attenuate waves (Fonseca \& Cahalan 1992, Koch \& Gust 1999, Verduin \& Backhaus 2000, Méndez \& Losada 2004). For example, Fonseca \& Cahalan (1992) found a reduction in wave energy density of approximately $40 \% \mathrm{~m}^{-1}$ of seagrass meadow during a laboratory study with 4 different seagrass species, and wave energy density reductions of up to $80 \%$ have been observed in the field (Prager \& Halley 1999). Coastal protection and management strategies need to account for the effect of seagrass on wave attenuation, and it is therefore important to understand which vegetation traits (e.g. shoot density, leaf length and stiffness) and hydrodynamic parameters (e.g. absence versus presence of current) drive wave attenuation by submerged vegetation (Teeter et al. 2001, Patil \& Singh 2009).

The effect of shoot density on wave attenuation has been recognised in a number of studies (e.g. Bouma et al. 2005, Chen et al. 2007, Augustin et al. 2009, Prinos et al. 2010), but the number of different densities 
used was generally low (2 to 3 ) and hence insufficient to derive in-depth insight in the relationship between shoot density and wave attenuation. Moreover, this relationship might be complicated by the effect of water depth. In general, wave attenuation by vegetation decreases if the submergence ratio (defined as the ratio of water depth to vegetation height) increases (Fonseca \& Cahalan 1992, Bouma et al. 2005, Augustin et al. 2009, Prinos et al. 2010). The influence of shoot density on wave attenuation also decreases with increasing submergence ratio, as shown for artificial salt marsh vegetation (Augustin et al. 2009) and Posidonia oceanica mimics (Prinos et al. 2010). Previously, the effect of submergence ratio on wave attenuation has mainly been addressed by changing the water depth over vegetation of constant height (e.g. Fonseca \& Cahalan 1992, Bouma et al. 2005, Augustin et al. 2009, Prinos et al. 2010). However, a change in water depth typically results in changed wave parameters such as wave height and/ or period, making it unclear whether this change in hydrodynamics influences the results. Thus, there is need to (1) study the relationship between shoot density and wave attenuation by covering a broader range of vegetation densities and (2) investigate the effect of submergence ratio on wave attenuation by maintaining a constant water depth while varying the vegetation height by using seagrasses with different shoot lengths.

A comparative study between seagrass and salt marsh species (Bouma et al. 2005) indicated that plant stiffness affects wave attenuation. The stiff salt marsh vegetation attenuated waves much more effectively than the flexible seagrass, which had a much larger amplitude of shoot movement with the waves. An increase of wave attenuation with increasing stiffness has also been observed for large macroalgae (Koehl 1996, Denny \& Gaylord 2002 and references therein). However, an effect of stiffness was not found when comparing a mimic showing cantilever motion to rigid structures (Augustin et al. 2009). When comparing wave attenuation over stiff Spartina anglica and flexible Puccinellia maritima marsh vegetation, Bouma et al. (2010) observed that differences in wave attenuation between flexible and stiff vegetation disappear on a biomass basis, meaning that an increased shoot density can counteract the reduced wave-attenuating capacity of flexible plants. While previous studies have indicated that stiffness can play a role in wave attenuation by vegetation, most studies have been carried out on vegetation types other than seagrass (i.e. salt marsh or macroalgae) and hence there is need for data on seagrass species with varying stiffness. The rigidity of a plant determines how much, and moreover in what way, a plant moves under the influence of waves. Depending on their stiffness and length, seagrasses move in a cantilever or a whip-like motion. A transition from the first to the latter can take place when the applied wave forcing increases (Manca 2010), and the rate of this transition varies with stiffness. It is not yet clear what role this type of motion plays in wave attenuation by seagrass.

In the past, laboratory studies have neglected the influence of a possible presence of a current on the wave-attenuating effect of vegetation. While this approach helps to understand the general processes of wave attenuation by vegetation, it is a simplification of the natural environment where most seagrass meadows are exposed to waves superimposed on a tidal flow. The effect of an underlying current on wave attenuation over unvegetated beds has been recognised (Madsen 1994), and a field study on kelp (Gaylord et al. 2003) investigated the effect of an alongshore current on wave forces. Those authors observed that the current perpendicular to wave propagation reduced wave energy dissipation for flexible kelp while it did not affect the wave-attenuating capacity of rigid structures. Moreover, the reduction within kelp increased with increasing flow velocity. To our knowledge, Gaylord et al. (2003) are the only researchers to date who have considered the effect of combined waves and currents, but the effect of a current on wave attenuation by seagrass has not yet been addressed.

In summary, previous studies have identified the vegetation characteristics shoot stiffness, shoot density and, indirectly, shoot length via the submergence ratio (i.e. ratio of water depth to vegetation height) as important factors in wave attenuation. However, a more systematic analysis of the effects that these traits have on wave attenuation is needed to understand how submerged vegetation like seagrass affects wave height (Bouma et al. 2010) and to be able to account for seagrass in coastal design (Fonseca \& Cahalan 1992). Within the existing studies on wave attenuation by vegetation, the effect of tidal currents is generally neglected, although a few studies have indicated that the presence of currents may be an important modifier on the wave-attenuating capacity of the plants. Hence, here we aimed to (1) investigate the impact of the 3 seagrass traits shoot stiffness, density and leaf length on wave height reduction and (2) investigate how a tidal current affects wave attenuation by seagrass. To disentangle the influence of specific vegetation traits on wave 
attenuation, simple but mechanically realistic seagrass mimics ( 2 stiffnesses, 5 densities, 3 lengths; see Table 1) were used in a series of flume experiments. By changing the mimics' leaf length, we addressed the effect of submergence ratio while maintaining identical wave conditions in constant water depth. To investigate how a tidal current affects wave attenuation by seagrass, mimics were exposed to waves with and without an underlying steady current.

\section{MATERIALS AND METHODS}

\section{Seagrass mimics}

Plant mimics were used in order to disentangle the impact of 3 seagrass traits (vegetation density, shoot flexibility and leaf length) on wave attenuation, while excluding effects of other morphological parameters. The use of mimics enabled us to change single traits while maintaining all other characteristics and therefore yielding information on the impact of single vegetation traits on hydrodynamics. Seagrass mimics have been successfully used in the laboratory (Bouma et al. 2005, Fonseca \& Koehl 2006, Ghisalberti \& Nepf 2006) and in field studies (Lee et al. 2001) and are widely accepted across disciplines. Fonseca \& Koehl (2006) used mimics to investigate hydrodynamics within and above seagrass meadows, while Lee et al. (2001) investigated the importance of seagrass to associated fauna with mimics. Additionally, mimics have also been widely applied in engineering studies (Stein et al. 1989).

The dimensions of the mimics were based on the natural size and density ranges of Zostera noltii in order to create scenarios similar to ones found in the

Table 1. Zostera noltii. Shoot density and leaf length for Z. noltii and mimics. All meadow mimics in the present study were exposed to waves with and without an underlying current

\begin{tabular}{|lccl|}
\hline $\begin{array}{l}\text { Vegetation } \\
\text { type }\end{array}$ & $\begin{array}{c}\text { Shoot density } \\
\left(\mathrm{m}^{-2}\right)\end{array}$ & $\begin{array}{c}\text { Leaf length } \\
(\mathrm{cm})\end{array}$ & Source \\
\hline Z. noltii & $4000-22000$ & $6-20$ & $\begin{array}{l}\text { Auby \& Labourg (1996) } \\
\text { Curiel et al. (1996) }\end{array}$ \\
& $4021-5400$ & $17.3-45.0$ & $\begin{array}{l}\text { Sfriso \& Ghetti (1998) } \\
\text { Flexible mimic }\end{array}$ \\
& $2030-14617$ & $<47.5$ & Paul \& Amos (2011) \\
& 1000 & $10 \& 15 \& 30$ & Present study \\
& 2000 & $10 \& 15 \& 30$ & Present study \\
& 4000 & $10 \& 15 \& 30$ & Present study \\
Stiff mimic & 8000 & $10 \& 15 \& 30$ & Present study \\
& 1000 & $10 \& 15$ & Present study \\
& 4000 & $10 \& 15$ & Present study \\
\hline
\end{tabular}

natural environment. $Z$. noltii was chosen because it has a simple and well described morphology (Den Hartog 1970). Its shoots consist of a stem or sheath and several ribbon-shaped leaves which can be easily reproduced in realistic mimics. Leaf width of all mimics ranged from 1.8 to $2.2 \mathrm{~mm}$, which represents the upper limit of the natural width of $Z$. noltii (Phillips \& Meñez 1988). Leaf lengths under investigation covered the natural range for $Z$. noltii and ranged from 10 to $30 \mathrm{~cm}$ (Table 1). By varying the leaf length, it was possible to investigate wave attenuation under different submergence ratios, but with constant water depth.

To explore the effect of stiffness on wave attenuation, we used mimics with 2 different flexibilities but otherwise comparable morphology. This approach is a simplification, as it is not to be expected that such differences in stiffness can be found within a single seagrass species. In nature, differences in stiffness would indicate a different species and consequently would always be accompanied by changes in morphology. However, this simplified approach enabled us to identify the effect of stiffness on wave attenuation without influences from other morphological parameters. It therefore puts the results in the context of wave attenuation by vegetation in general instead of by just 1 species. The mimic materials were chosen in a way that they showed a different bending behaviour. The stiff mimic (cable ties) was similar to mimics that have been used to represent salt marsh vegetation (Bouma et al. 2005) and moved like a cantilever under wave motion (Fig. 1a). The flexible material (poly ribbon) bent similarly to Zostera noltii plants and at high leaf lengths showed a whip-like motion under waves (Fig. 1b). For both flexibilities, mimic meadows with a density of 1000 and 4000 shoots $\mathrm{m}^{-2}$ were produced. For the flexible mimics, additional meadow mimics with densities of 500, 2000 and 8000 shoots $\mathrm{m}^{-2}$ were generated. These densities cover a wide range of natural densities of $Z$. noltii (Table 1) and yield a detailed investigation of the impact of shoot density on wave attenuation.

The combination of the above flexibilities, densities and leaf lengths led to a total number of 19 different meadow mimics (Table 1). Each meadow mimic was $3 \mathrm{~m}$ long and $0.6 \mathrm{~m}$ wide to cover the whole width of the flume (see 'Experimental setup' below). To create the meadow, the 
a

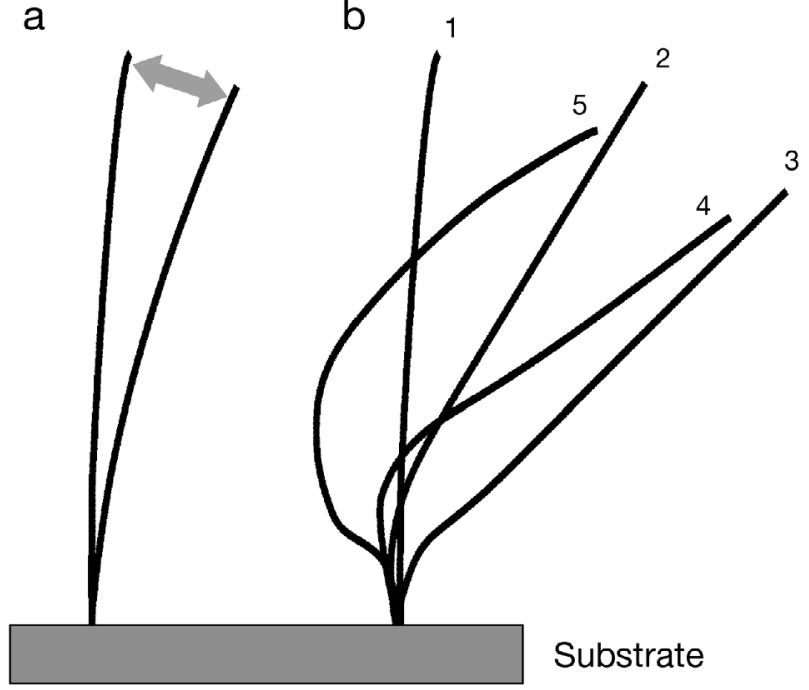

Fig. 1. Schematic representation of mimic movement. (a) The stiff material moves back and forth like a cantilever, and (b) the flexible material moves in a whip-like motion mimics were tied to a canvas mesh with a mesh size of $0.8 \mathrm{~cm}$. To achieve an evenly distributed and yet arbitrarily organised meadow mimic that would be comparable to a natural distribution in the field, the canvas was segmented into squares of $3.4 \times 3.4 \mathrm{~cm}$. For the density of 1000 shoots $\mathrm{m}^{-2}, 1$ strip was placed haphazardly within each square. For the other densities, the number of strips per square was reduced or increased accordingly. For each meadow mimic, the canvas was then attached to a wooden board, and the board was weighed down on the bottom of the flume for deployments.

\section{Experimental setup}

Experiments were carried out under controlled conditions in a racetrack wave flume (Fig. 2a). The oval flume was $0.6 \mathrm{~m}$ wide and had a straight working section of $10.8 \mathrm{~m}$. Water depth up to $0.4 \mathrm{~m}$ could be main-

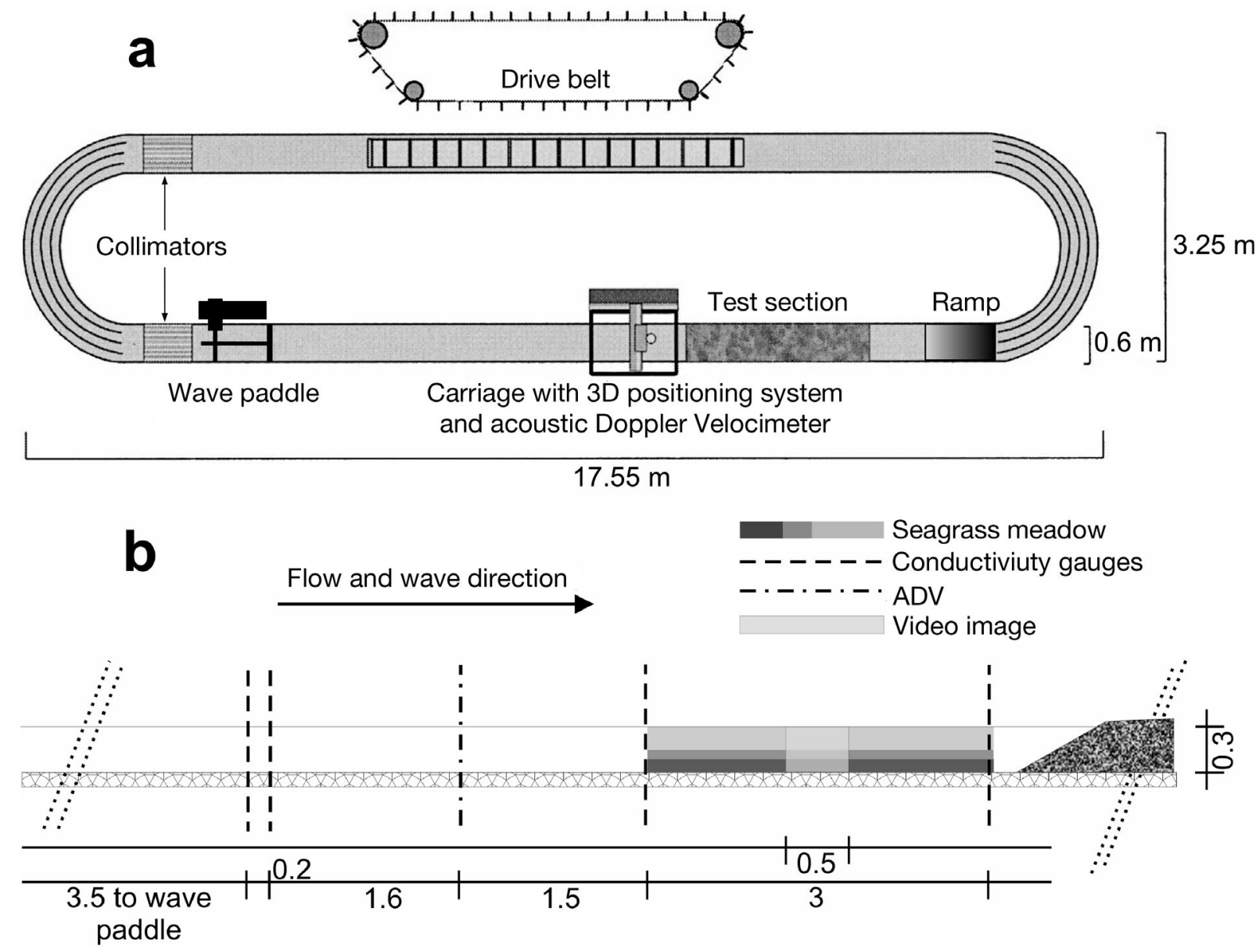

Fig. 2. Schematic representation of (a) the flume (adapted from Bouma et al. 2005) and (b) the setup of instruments (all dimensions in $\mathrm{m}$ ) 
tained (Hendriks et al. 2006). The flume was equipped with a conveyor belt system and a wave paddle. This combination allowed generating unidirectional flow with velocities up to $0.45 \mathrm{~m} \mathrm{~s}^{-1}$ (Bouma et al. 2007), waves of varying heights and periods (Chang et al. 2008) or a combination of both. This feature provided us with the opportunity to investigate the influence of vegetation traits on waves only as well as on combinations of waves and steady currents. The latter represent more natural conditions where tidal currents act simultaneously with waves. However, only an incoming tide can be represented during the experiments, as flow and waves could only be generated in the same direction. Additionally, the size of the flume enabled us to run the experiments on full scale and therefore eliminated possible errors that might occur during down-scaling of the mimics.

The water depth in the flume was set to $0.3 \mathrm{~m}$, which allowed a submergence ratio of 1:1, 2:1 and 3:1 for the respective leaf lengths. All of these ratios can be observed in the field (Koch 1994, Curiel et al. 1996). Regular waves with a wave height of $H=0.1 \mathrm{~m}$ and a wave period of $T \approx 1 \mathrm{~s}$ were generated by the wave paddle. The waves were applied to all meadow mimics once without and once with an underlying steady current of $0.1 \mathrm{~m} \mathrm{~s}^{-1}$, which corresponds to low tidal currents typical for areas covered with seagrass in the field (Bouma et al. 2005). Additionally, a control run in an empty flume was carried out for both hydrodynamic conditions.

Wave height was measured with 4 conductivity gauges (DHI) at a sampling rate of $25 \mathrm{~Hz}$, and recordings were taken for $600 \mathrm{~s}$ for each run (Fig. 2b). Two of the gauges were placed $3.3 \mathrm{~m}$ in front of the seagrass mimics and spaced $21.5 \mathrm{~cm}$ apart to detect occurring reflection. One gauge was placed at the leading edge of the seagrass mimics and 1 at the end of the mimics. Additionally, a video camera was used to record seagrass movement through the glass wall of the test section, and an acoustic doppler velocimeter (ADV) was used to monitor flow velocities. The filmed section was located $1.5 \mathrm{~m}$ into the mimic patch, and film sequences were $300 \mathrm{~s}$ long for each run.

\section{Data processing}

Wave recordings were transformed into the frequency domain using Fast Fourier Transform. The data from the 2 upstream gauges were used to determine the reflection coefficient using the method developed by Baldock \& Simmonds (1999). Data from the gauges at the beginning and end of the seagrass mimics were filtered for the determined reflection if the reflection coefficient exceeded $5 \%$. Data were then transformed back into the time domain with an Inverse Fast Fourier Transform, and 0-crossing was applied to obtain significant wave height at the beginning and end of the seagrass mimics. From these values, the dissipated wave height $\Delta H$ per meter of mimic patch was derived as:

$$
\Delta H=\left(H_{1}-H_{2}\right) / x
$$

where $H_{1}$ and $H_{2}$ are the wave heights at the beginning and end of the seagrass mimics, respectively, and $x$ is the length of the mimic patch $(3 \mathrm{~m})$. This approach assumes linear wave dissipation along the patch. Previous studies have shown that the relationship between wave dissipation and distance into a vegetated area is non-linear (Möller et al. 1999, Koch et al. 2009, Bouma et al. 2010). However, linearity is a valid simplification when studying flexible vegetation with relatively small wave-attenuating capacity over short distances (Fonseca \& Cahalan 1992, Bouma et al. 2005).

As the mimic meadows varied in leaf length as well as density, a parameter that includes both of these values was required to compare all flume runs with each other. Therefore, the 1-sided leaf area index $\left(\mathrm{LAI}=\right.$ leaf length $\times$ leaf width $\times$ density, $\mathrm{m}^{2} \mathrm{~m}^{-2}$ ) was calculated for each meadow mimic and consequently used to compare the wave-attenuating capacity of each meadow mimic under investigation.

Relationships between dissipated wave height and influencing parameters were explored for a best fit. In cases where the fit was significant, it was found to be linear. Stepwise multiple regression was then applied to evaluate the influence of all parameters under investigation (i.e. LAI, stiffness, submergence ratio, current) on dissipated wave height.

Plant movement was expressed in excursion of the leaf tip, which was derived from video recordings. A transparent sheet was placed in front of the computer screen while the video was played back. The maximum excursion of 10 leaves run ${ }^{-1}$ was marked on the sheet and later measured. Those distances were scaled to full scale using the known height of the window in the flume wall. The video recordings were also used to determine canopy height for each run. Canopy height was defined as distance above the bed that contained seagrass. It can be smaller than the mimic's leaf length if the mimic is bending under incident forcing.

The force required to deflect the stiff mimic from the vertical was measured with a strain gauge (Gould). The gauge was attached to the tip of a $15 \mathrm{~cm}$ 
long mimic and pulled sideways; readings were taken when the mimic's tip reached the respective angle. Due to the gauge design, these measurements were carried out in air. Values will therefore differ from forces required in water; however, this difference is expected to be constant, and the values in air show the general relationship between force and deflected angle.

\section{RESULTS}

For all mimic meadows, an increased wave height reduction was observed compared to the reduction during control runs with a bare bottom (see Figs. 3 to 5). Additionally, an effect of plant stiffness on wave attenuation was clear when comparing the results from both materials used (Fig. 3). The attenuating effect of the stiff material was approximately 4 times higher for any given LAI compared to the flexible mimics, unless LAI was negligibly low.

For both stiffnesses, the dependence of wave dissipation on LAI was best described by a linear relationship (Fig. 3): $\Delta H=0.61 \times \mathrm{LAI}+0.56\left(\mathrm{n}=5, \mathrm{R}^{2}=0.94\right)$ and $\Delta H=0.14 \times \mathrm{LAI}+0.57\left(\mathrm{n}=15, \mathrm{R}^{2}=0.85\right)$ for the stiff and flexible mimic, respectively. The relationships differ significantly in slope $(t$-test, $p<0.05)$, while the intercepts are comparable and slightly higher than the control value. We do not know why a discrepancy between regression intercepts and control value exists.

Moreover, our results showed that wave dissipation increases with submergence ratio (Fig. 4). However, the data suggest that the effect of submergence ratio remains almost constant for shoot densities

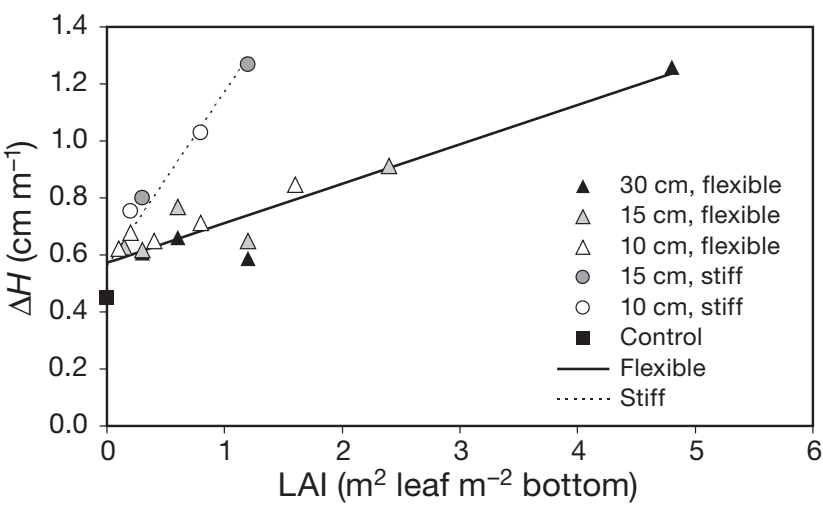

Fig. 3. Dissipated wave height $\left(\Delta H, \mathrm{~cm} \mathrm{~m}^{-1}\right)$ as a function of leaf area index (LAI) under waves only. The square indicates the value without any seagrass in the flume. Linear regression yields for the flexible material $\Delta H=0.14 \times \mathrm{LAI}+0.57\left(\mathrm{R}^{2}=\right.$ $0.85)$ and for the stiff material $\Delta H=0.61 \times \mathrm{LAI}+0.56\left(\mathrm{R}^{2}=0.94\right)$

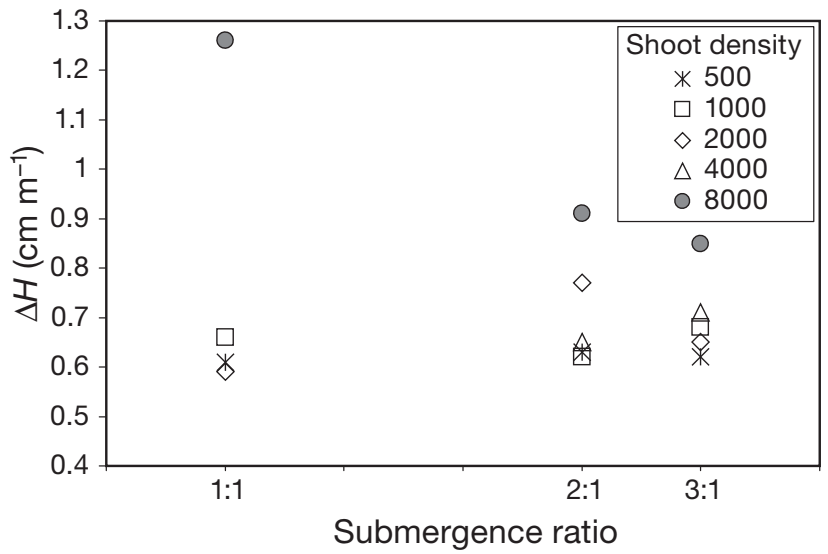

Fig. 4. Relationship between dissipated wave height $\Delta H$ and submergence ratio for various shoot densities $\left(\mathrm{m}^{-2}\right)$

$\leq 2000 \mathrm{~m}^{-2}$ and increases with increasing density above this value.

Comparing wave attenuation in the absence or presence of an underlying current of $0.1 \mathrm{~m} \mathrm{~s}^{-1}$ revealed that if a current is present, both wave dissipation and the observed canopy height are reduced for any given leaf length (Fig. 5). The canopy height reduction by currents is up to $36 \%$ for the flexible material, with the largest reduction for long flexible
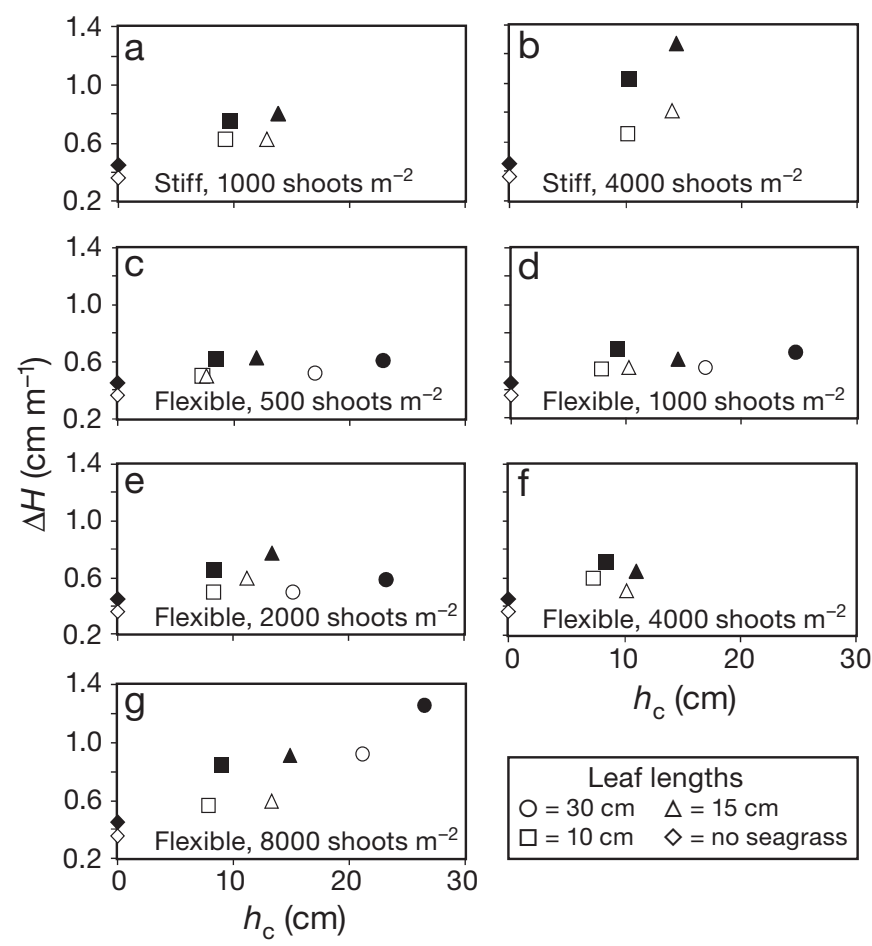

Fig. 5. Dissipated wave height $\Delta H$ as a function of canopy height $h_{\mathrm{c}}$. Data for the wave-only case are represented by black symbols; data for the combined wave and current case are represented by white symbols 
leaves compared to shorter ones (Fig. 5c to g) and, not surprisingly, much smaller for the stiff material (up to $7 \%$, Fig. 5a,b). Leaf bending due to currents puts leaves lower in the water column where they are exposed to less orbital motion. However, even when comparing mimics with a similar actual canopy height (Fig. 5), wave dissipation rates in the presence of a current are $>10 \%$ lower than in the absence of a current. This indicates that processes other than the position of the leaves in the water column cause the observed reduction in wave attenuation in the presence of a current.

Another parameter that was reduced in the presence of an underlying current was the excursion of the mimic's tip; it changed with leaf length, but more importantly with the presence of a current. At the highest shoot densities for both stiffnesses, a reduction in tip excursion of 16 to $28 \%$ was observed in the presence of a current (Table 2).

When considered individually, stiffness, LAI, submergence ratio and current have an effect on wave height dissipation. However, results also indicate that stiffness and LAI can compensate each other (Fig. 3). Moreover, due to the setup of the experiments, a decrease in submergence ratio led to an increase in LAI for a given shoot density (Fig. 4), which needs to be taken into account when interpreting the effect of submergence ratio on wave attenuation. To explore possible interdependences, stepwise multiple regression was carried out on the whole dataset (Table 3).

Regression results show that compared to other parameters in this study, submergence ratio has no significant effect on wave height dissipation ( $\beta=0.05$, $t=0.54, \mathrm{p}>0.5$ ). From the other parameters, LAI is the dominating factor when estimating wave height dissipation, followed by the effect of an underlying current (Table 3). Stiffness has also been identified as

Table 2. Difference in tip excursion between treatments with waves only (no current) and with combined waves and currents (with current). Reduction of tip excursion is expressed in absolute terms and as a percentage of the no-current value. Variability is expressed by the SE

\begin{tabular}{|c|c|c|c|c|c|}
\hline \multirow[t]{2}{*}{ Mimic type } & \multirow{2}{*}{$\begin{array}{l}\text { Leaf length } \\
\qquad(\mathrm{cm})\end{array}$} & \multicolumn{2}{|c|}{ Tip excursion (cm) } & \multicolumn{2}{|c|}{ Reduction } \\
\hline & & No current & With current & $\begin{array}{l}\text { Absolute } \\
\text { (cm) }\end{array}$ & $\%$ \\
\hline \multirow{3}{*}{$\begin{array}{l}\text { Flexible, } \\
8000 \text { shoots } \mathrm{m}^{-2}\end{array}$} & 30 & $5.50 \pm 0.36$ & $4.12 \pm 0.22$ & 1.38 & 25 \\
\hline & 15 & $4.50 \pm 0.17$ & $3.76 \pm 0.18$ & 0.74 & 16 \\
\hline & 10 & $3.07 \pm 0.10$ & $2.55 \pm 0.09$ & 0.52 & 17 \\
\hline Stiff, & 15 & $5.56 \pm 0.11$ & $3.98 \pm 0.20$ & 1.58 & 28 \\
\hline 4000 shoots $\mathrm{m}^{-2}$ & 10 & $3.99 \pm 0.10$ & $3.06 \pm 0.11$ & 0.93 & 23 \\
\hline
\end{tabular}

Table 3. Results of stepwise multiple regression for vegetation traits and currents under investigation. $b=$ regression coefficient, $\beta=$ standardised regression coefficient. The regression was done in SPSS with the criteria Probability-of-Fto-enter $\leq 0.05$ and Probability-of-F-to-remove $\geq 0.1$. The effect of submergence ratio was not significant ( $p>0.25$ for all models). Values for $\beta$ are at $p<0.001$. LAI: leaf area index

\begin{tabular}{|lrrrr|}
\hline \multicolumn{1}{l}{$b$} & $\mathrm{SE} b$ & $\beta$ & $\mathrm{R}^{2}$ \\
\hline Model 1 & & & & 0.32 \\
Constant & 0.59 & 0.04 & & \\
LAI & 0.10 & 0.02 & 0.57 & \\
& & & & \\
Model 2 & & & & 0.57 \\
Constant & 0.69 & 0.04 & & \\
LAI & 0.10 & 0.20 & 0.57 & \\
Current & -1.87 & 0.43 & -0.50 & \\
& & & & \\
Model 3 & & & & 0.80 \\
Constant & 0.41 & 0.05 & & \\
LAI & 0.11 & 0.01 & 0.65 & \\
Current & -1.87 & 0.30 & -0.50 & \\
Stiffness & 0.22 & 0.04 & 0.48 & \\
\hline
\end{tabular}

significant, but the values for the regression coefficient $b$ and the standardised regression coefficient $\beta$ need to be interpreted with caution. As no quantitative measurements of stiffness were carried out during this study, stiffness was included as an indexed value in the regression analysis.

\section{DISCUSSION}

We investigated the combined effect of vegetation characteristics (shoot stiffness, density and length) and the presence/absence of an underlying current on wave attenuation by submerged (mimic) vegetation. By using mimic meadows with different shoot densities and leaf lengths under constant hydrodynamic conditions, we found that for a given water depth, wave attenuation of shallow water waves depends on LAI. This observation applied to both stiffnesses used in this study; however, wave attenuation for a given LAI was much more pronounced for the stiff material. Additionally, tests with and without an underlying current revealed, to our knowledge for the first time, that the wave-attenuating capacity of seagrass is significantly lower in the presence of a current. 


\section{Stiffness}

The materials chosen for the mimics strongly differed in stiffness, which led to a different bending behaviour (cantilever versus whip-like) under waves and resulted in different rates of wave attenuation. This agrees with a study carried out on real plants of contrasting stiffness (Bouma et al. 2005). A comparison between rigid and cantilever-like structures, however, did not yield a significant difference in wave attenuation (Augustin et al. 2009). Hence, it is possible that the type of motion (cantilever versus whip-like) is more important for wave attenuation than the material stiffness as such. A study on Spartina anglica and Puccinellia maritima (Bouma et al. 2010) found that the flexible plant ( $P$. maritima) dissipated wave height at higher densities as effectively as the stiff plant $(S$. anglica) did at low densities. This observation was confirmed in the present study, where the flexible material required approximately 4 times the LAI of the stiff material to yield the same dissipated wave height.

\section{Submergence ratio and LAI}

Previous studies (Ward et al. 1984, Fonseca \& Cahalan 1992, Koch 1996) showed that seagrass is more effective at attenuating waves when it occupies more of the water column. This led to the general understanding that wave attenuation depends on the submergence ratio. Our results extend these observations by showing that for a given small water depth, LAI as a combination of leaf length and shoot density can be used as an integrating factor to predict wave attenuation.

In field studies (Ward et al. 1984, Koch 1996, Koch et al. 2006) the seagrass canopy remained constant and water depth changed over the tidal cycle. As a result of changing water depth, wave height and period are likely to have changed. Paul \& Amos (2011) showed that waves of different periods are attenuated differently by a Zostera noltii bed, and it is possible that this response to differing wave periods is responsible for the difference in wave-attenuation capacity with varying water depth. Fonseca \& Cahalan (1992) varied water depth during their laboratory study on 4 different seagrass species, and although they applied waves with the same period, incident wave height varied between runs. Other laboratory studies adopted this approach and also changed the submergence ratio by adjusting water depth over vegetation with constant height (Augustin et al. 2009, Prinos et al. 2010).
During our study, variation in submergence ratio was achieved by exposing mimics with different leaf lengths to identical monochromatic waves in constant water depth. For a constant incident wave forcing, our study confirmed previous findings that wave dissipation depends on submergence ratio (Fonseca \& Cahalan 1992, Prinos et al. 2010). A linear trend was found for all shoot densities under investigation (Fig. 4), but the trends for shoot densities $\leq 2000 \mathrm{~m}^{-2}$ did not differ significantly. This finding agrees with observations made in the field, where a minimum shoot density was required to observe wave attenuation in Zostera noltii (Paul \& Amos 2011) and Ruppia maritima (Newell \& Koch 2004). However, it may be an artefact of the dataset, as data for 2000 shoots $\mathrm{m}^{-2}$ did not show good correlation $\left(\mathrm{R}^{2}=0.15\right)$ and the density of 4000 shoots $\mathrm{m}^{-2}$ lacks data for a submergence ratio of 1:1. Moreover, stepwise multiple regression (Table 3) showed that the effect of submergence ratio was not significant when explaining observed dissipated wave height across the whole dataset. This lack of significance may be due to the experimental setup. To achieve different submergence ratios in constant water depth, the mimics' leaf lengths were adjusted between runs. This led to an increase of LAI with decreasing submergence ratio for a given shoot density. LAI was identified as the main influencing parameter for wave height dissipation and therefore may have affected the relationship observed for submergence ratio and dissipated wave height in this case.

The results also revealed a linear relationship of wave dissipation with LAI (Fig. 3). This suggests that for a given wave in shallow water, a short but dense meadow has the same wave-attenuating effect as a high but sparse meadow with the same LAI. This may be explained by the drag that each unit of leaf area poses on the water movement which in return loses momentum (Kobayashi et al. 1993). The sum of momentum loss generated by the whole leaf area leads to reduced wave energy and can be observed as wave height reduction. As a result, it may not matter where in the water column the biomass is located, and only the amount of biomass determines the rate of wave attenuation. However, we expect this to be only valid for cases where the waves are in shallow water and feel the bottom. In cases where the orbital wave motion does not reach the bottom, a higher meadow is likely to have a higher attenuating effect, because the wave would feel part of the long leaves while it may not feel a shorter meadow. Moreover, this conclusion is based on meadows where biomass is evenly distrib- 
uted throughout the height of the canopy (e.g. Zostera noltii), and it is not yet known whether the same applies to species that have more biomass in the upper (Amphibolis antarctica) or lower (Posidonia oceanica) part of the canopy.

\section{Effect of current}

In the presence of a current, wave attenuation shows the same systematic behaviour as in the waveonly case, but dissipated wave height is lower for a given canopy height when a current is present (Fig. 5). A reduction in wave attenuation was also observed in the control runs which could be explained by the increased wavelength due to the Doppler effect that sets in when a current follows waves (Demirbilek et al. 1996). It has been observed that wave attenuation decreases with increasing wavelength (Nielsen 1992). However, during the control runs, the effect of the underlying current on wave attenuation was generally small compared to the current's effect on wave attenuation by mimics (i.e. on average $45 \%$ less effect on controls). Overall, our results clearly indicate that the current has an important effect on the wave-attenuating capacity of seagrass.

To our knowledge, no other study to date has addressed the influence of a current on wave attenuation by seagrass systematically, although its effect on wave attenuation has been recognised for unvegetated beds (Madsen 1994) and kelp (Gaylord et al. 2003). Our results confirm that the same is true for seagrass beds and suggest that previous studies which neglected the effect of underlying currents may have overestimated the effect of seagrass on wave attenuation in tidal regions, especially in cases where the underlying current follows the waves.

Wave attenuation by vegetation has 3 components. Plants (1) provide skin friction due to their surface structure, (2) impose form drag on the flow that depends on their shape and (3) absorb wave energy by converting it into plant movement. Skin friction generally depends on the size of the wetted plant area, although this can change when flexible organisms bend or packaging occurs at high densities (Koehl 1996). Under the tested conditions, however, it can be considered independent of flow velocities. The form drag of the plant's frontal area generates turbulence behind the plant, which leads to energy dissipation (Nepf 1999). In the presence of a current, flexible plants change their shape by bending, which reduces the frontal area that poses drag on the flow (Vogel 1994, Boller \& Carrington 2006). This stream- lining allows flexible plants to reduce form drag under increased flows compared to rigid structures (Vogel 1984, Koehl 1996), which in turn may contribute to the reduction in wave attenuation in the presence of a current. However, the effect of bending on wave attenuation is considered small, because the orbital wave motion prevents a constant state of streamlining over the wave cycle.

Vegetation also reduces wave energy by transforming it into plant movement. This transformation results in less energy contained in the wave and can thus be observed in a reduced wave height, because the 2 parameters are related according to linear wave theory (Kamphuis 2000). In the wave-only case, seagrass can move freely within the limits of its stiffness and extract energy from the waves. In the presence of a current, this movement gets restricted (Table 2) and the plants are therefore no longer able to absorb the same amount of wave energy.

An underlying current exerts an initial force on the plants which causes them to bend. This bending leads to a primary tension within the blades, and the force required to bend the blade further increases with increasing bending angle (Fig. 6). The plant movement generated by a given wave force would therefore decrease if the initial bend due to a steady current increases. A study under unidirectional flow (Boller \& Carrington 2006) showed that initially flexible macroalgae were affected by flow velocities and behaved like rigid bodies once a critical velocity was exceeded. It could therefore be expected that the motion-restrictive nature of the underlying current would increase with increasing flow velocity. Similar to macroalgae (Boller \& Carrington 2006), it may be

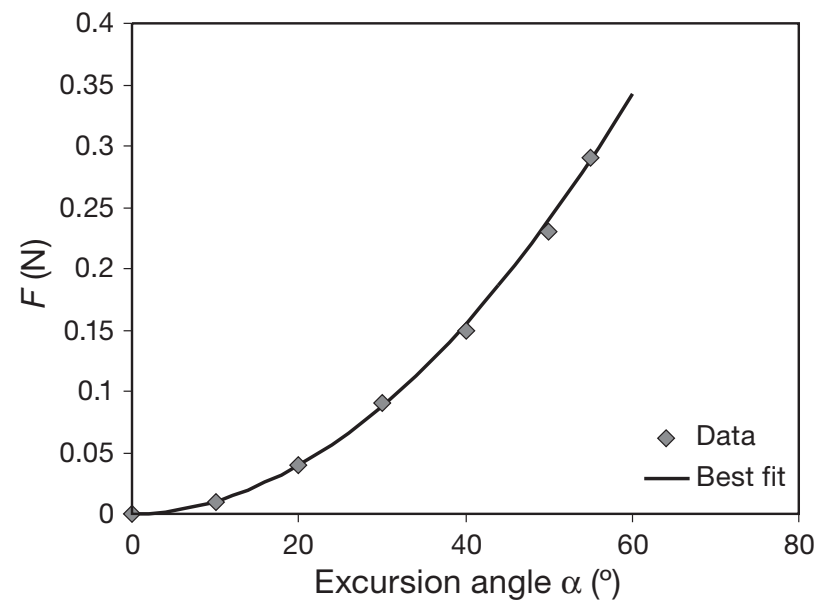

Fig. 6. Required force $F$ to deflect the stiff mimic from the vertical. The relationship can be described by $F=10^{-4} \times \alpha^{2}$ $\left(\mathrm{R}^{2}=0.99\right)$ 
possible that a critical velocity exists at which the seagrass blades are not able to move anymore and wave attenuation would remain constant when flow velocities increase above this threshold value. We hypothesise that the wave attenuation of plants that are exposed to currents above this threshold would still be higher than wave attenuation in the complete absence of plants due to skin friction and streamlined form drag.

The stiff material in this experiment did not bend significantly, and its motion can be described as the back and forth movement of a cantilever (Fig. 1a). The flexible material, however, did bend under waves as well as under combined waves and currents and showed a whip-like motion when it moved against the direction of wave propagation (Fig. 1b). This whip-like motion was equally apparent in the presence and absence of a current, but with a smaller excursion when a current was present. The above explanation would therefore be valid for material that has a cantilever motion as well as for material with a whip-like motion and may be applicable for a wide range of vegetation types.

\section{CONCLUSIONS}

Laboratory experiments with artificial seagrass were used to investigate the effect of leaf length, shoot density and stiffness on wave attenuation in the absence and presence of a tidal current. Results showed that LAI is the dominating factor that determines wave attenuation. The LAI combines the effect of leaf length and shoot density and therefore indicates that density can compensate for lack of canopy height and vice versa with respect to wave attenuation. Shoot stiffness was also found to be significant, although its impact could not be finally quantified within this study. On the other hand, the impact of submergence ratio was not significant, which contrasts previous findings (Fonseca \& Cahalan 1992). This difference in observations may be caused by different experimental setups, but further work is required to clarify the effect of submergence ratio on wave attenuation. The presence of an underlying current led to a reduction in wave attenuation for all 19 mimic meadows under investigation. This clearly shows that experiments which are carried out under waves only are likely to overestimate the wave-attenuating capacity of seagrass compared to most natural environments where underlying currents are present in the form of tidal flow.
Acknowledgements. We acknowledge the use of MatLab code for 0 -crossing and wave reflection kindly provided by U. Neumeier and T. Baldock, respectively. The laboratory experiments were possible thanks to a Peter Killworth Memorial Scholarship, and M.P. thanks C. and D. Paul for uncounted hours of invaluable help during preparation and execution of the experiments. The remarks from 3 anonymous reviewers helped to improve the manuscript.

\section{LITERATURE CITED}

Auby I, Labourg PJ (1996) Seasonal dynamics of Zostera noltii Hornem. in the bay of Arcachon (France). J Sea Res 35:269-277

Augustin LN, Irish JL, Lynett P (2009) Laboratory and numerical studies of wave damping by emergent and nearemergent wetland vegetation. Coast Eng 56:332-340

Baldock TE, Simmonds DJ (1999) Separation of incident and reflected waves over sloping bathymetry. Coast Eng 38: 167-176

Boller ML, Carrington E (2006) The hydrodynamic effects of shape and size change during reconfiguration of a flexible macroalga. J Exp Biol 209:1894-1903

> Bouma TJ, De Vries MB, Low E, Peralta G, Tánczos IC, van de Koppel J, Herman PMJ (2005) Trade-offs related to ecosystem engineering: a case study on stiffness of emerging macrophytes. Ecology 86:2187-2199

- Bouma TJ, van Duren LA, Temmerman S, Claverie T, Blanco-Garcia A, Ysebaert T, Herman PMJ (2007) Spatial flow and sedimentation patterns within patches of epibenthic structures: combining field, flume and modelling experiments. Cont Shelf Res 27:1020-1045

Bouma TJ, De Vries MB, Herman PMJ (2010) Comparing ecosystem engineering efficiency of two plant species with contrasting growth strategies. Ecology 91:2696-2704

Chang ER, Veeneklaas RM, Buitenwerf R, Bakker JP, Bouma TJ (2008) To move or not to move: determinants of seed retention in a tidal marsh. Funct Ecol 22:720-727

Chen SN, Sanford LP, Koch EW, Shi F, North EW (2007) A nearshore model to investigate the effects of seagrass bed geometry on wave attenuation and suspended sediment transport. Estuaries Coasts 30:296-310

Curiel D, Bellato A, Rismondo A, Marzocchi M (1996) Sexual reproduction of Zostera noltii Hornemann in the lagoon of Venice (Italy, north Adriatic). Aquat Bot 52:313-318

Demirbilek Z, Dalrymple RA, Sorenson RM, Thompson EF, Weggel JR (1996) Water waves. In: Heggen RJ (ed) Hydrology handbook. American Society of Civil Engineers, New York, NY, p 627-720

Den Hartog C (1970) The sea-grasses of the world. North Holland Publishing Company, Amsterdam

> Denny M, Gaylord B (2002) The mechanics of wave-swept algae. J Exp Biol 205:1355-1362

Fonseca MS (1996) The role of seagrasses in nearshore sedimentary processes: a review. In: Nordstrom KF, Roman CT (eds) Estuarine shores: evolution, environments and human alterations. Wiley, Chichester, p 261-286

Fonseca MS, Cahalan JA (1992) A preliminary evaluation of wave attenuation by four species of seagrass. Estuar Coast Shelf Sci 35:565-576

Fonseca MS, Fisher JS (1986) A comparison of canopy friction and seagrass movement between four species of seagrass with reference to their ecological restoration. Mar Ecol 29:15-22 
Fonseca MS, Koehl MAR (2006) Flow in seagrass canopies: the influence of patch width. Estuar Coast Shelf Sci 67:1-9

Gaylord B, Denny MW, Koehl MAR (2003) Modulation of wave forces on kelp canopies by alongshore currents. Limnol Oceanogr 48:860-871

Ghisalberti M, Nepf HM (2006) The structure of the shear layer over rigid and flexible canopies. Environ Fluid Mech 6:277-301

Hendriks IE, van Duren LA, Herman PMJ (2006) Turbulence levels in a flume compared to the field: implications for larval settlement studies. J Sea Res 55:15-29

Kamphuis JW (2000) Introduction to coastal engineering and management. World Scientific, Singapore

Kobayashi N, Raichle AW, Asano T (1993) Wave attenuation by vegetation. J Waterw Port Coast Ocean Eng 119:30-48

Koch EW (1994) Hydrodynamics, diffusion-boundary layers and photosynthesis of the seagrasses Thalassia testudinum and Cymodocea nodosa. Mar Biol 118:767-776

Koch EW (1996) Hydrodynamics of a shallow Thalassia testudinum bed in Florida, U.S.A. In: Kuo J, Phillips RC, Walker DI, Kirkman H (eds) Seagrass biology: proceedings of an international workshop, Faculty of Sciences, University of Western Australia, Nedlands, p 105-109

Koch EW, Gust G (1999) Water flow in tide- and wave-dominated beds of the seagrass Thalassia testudinum. Mar Ecol Prog Ser 184:63-72

Koch EW, Ackerman JD, Verduin JJ, van Keulen M (2006) Fluid dynamics in seagrass ecology: from molecules to ecosystems. In: Larkum AWD, Orth RJ, Duarte CM (eds) Seagrasses: biology, ecology and conservation. Springer, Berlin, p 193-225

Koch EW, Barbier EB, Silliman BR, Reed DJ and others (2009) Non-linearity in ecosystem services: temporal and spatial variability in coastal protection. Front Ecol Environ 7:29-37

Koehl MAR (1996) When does morphology matter? Annu Rev Ecol Syst 27:501-542

> Lee SY, Fong CW, Wu RSS (2001) The effects of seagrass (Zostera japonica) canopy structure on associated fauna: a study using artificial seagrass units and sampling of natural beds. J Exp Mar Biol Ecol 259:23-50

Madsen OS (1994) Spectral wave-current bottom boundary layer flows. In: Edge BL (ed) 24th Conf Coast Eng. American Society of Civil Engineering, Kobe, p 384-398

Manca E (2010) Effects of Posidonia oceanica seagrass on nearshore waves and wave-induced flows. PhD thesis, University of Southampton

> Méndez FJ, Losada IJ (2004) An empirical model to estimate the propagation of random breaking and nonbreaking waves over vegetation fields. Coast Eng 51:103-118

Möller I, Spencer T, French JR, Leggett DJ, Dixon M (1999) Wave transformation over salt marshes: a field and numerical modelling study from north Norfolk, England.

Editorial responsibility: Just Cebrian,

Dauphin Island, Alabama, USA
Estuar Coast Shelf Sci 49:411-426

Nepf HM (1999) Drag, turbulence, and diffusion in flow through emergent vegetation. Water Resour Res 35: 479-489

> Newell RIE, Koch EW (2004) Modeling seagrass density and distribution in response to changes in turbidity stemming from bivalve filtration and seagrass sediment stabilization. Estuaries 27:793-806

Nielsen P (1992) Coastal bottom boundary layers and sediment transport. World Scientific Publishing, Singapore

Patil S, Singh VP (2009) Hydrodynamics of wave and current vegetation interaction. J Hydrol Eng 14:1320-1333

> Paul M, Amos CL (2011) Spatial and seasonal variation in wave attenuation over Zostera noltii. J Geophys Res 116: C08019. doi:10.1029/2010JC006797

Phillips RC, Meñez EG (1988) Seagrasses. Smithson Contrib Mar Sci 34

Prager EJ, Halley RB (1999) The influence of seagrass on shell layers and Florida bay mudbanks. J Coast Res 15: 1151-1162

Prinos P, Stratigaki V, Manca E, Losada IJ and others (2010) Wave propagation over Posidonia oceanica: large scale experiments. In: Grüne J, Klein Breteler M (eds) Proc Hydralab III Joint Transnational Access User Meeting, Hannover, p 57-60

Sfriso A, Ghetti PF (1998) Seasonal variation in biomass, morphometric parameters and production of seagrasses in the lagoon of Venice. Aquat Bot 61:207-223

Stein D, Arns L, Eichweber G, Faubel A, Regier M (1989) Erosionsschutz im Seewasserbau - Untersuchung der Wirkung von künstlichen Seegrasmatten auf Sedimentationsvorgänge. Schlussbericht BMFT FB. Ruhr-Universtität Bochum, Fakultät Bauingenieurwesen, Bochum

Teeter AM, Johnson BH, Berger C, Stelling G, Scheffner NW, Garcia MH, Parchure TM (2001) Hydrodynamic and sediment transport modelling with emphasis on shallow-water, vegetated areas (lakes, reservoirs, estuaries and lagoons). Hydrobiologia 444:1-23

Verduin JJ, Backhaus JO (2000) Dynamics of plant-flow interactions for the seagrass Amphibolis antarctica: field observations and model simulations. Estuar Coast Shelf Sci 50:185-204

Verduin JJ, Backhaus JO, Walker DI (2002) Estimates of pollen dispersal and capture within Amphibolis antarctica (Labill.) Sonder and Aschers. ex Aschers. meadows. Bull Mar Sci 71:1269-1277

Vogel S (1984) Drag and flexibility in sessile organisms. Am Zool 24:37-44

Vogel S (1994) Life in moving fluids: the physical biology of flow. Princeton University Press, Princeton, NJ

- Ward LG, Kemp WM, Boynton WE (1984) The influence of waves and seagrass communities on suspended particulates in an estuarine embayment. Mar Geol 59:85-103

Submitted: February 7, 2011; Accepted: November 7, 2011 Proofs received from author(s): December 29, 2011 